\title{
Beyond communication training: The MaRIS model for developing medical students' human capabilities and personal resilience
}

\section{Kwong D. Chan, Linda Humphreys, Amary Mey, Carissa Holland, Cathy Wu \&} Gary D. Rogers

To cite this article: Kwong D. Chan, Linda Humphreys, Amary Mey, Carissa Holland, Cathy Wu \& Gary D. Rogers (2020) Beyond communication training: The MaRIS model for developing medical students' human capabilities and personal resilience, Medical Teacher, 42:2, 187-195, DOI: 10.1080/0142159X.2019.1670340

To link to this article: https://doi.org/10.1080/0142159X.2019.1670340
( ) 2019 The Author(s). Published by Informa UK Limited, trading as Taylor \& Francis Group.

\section{曲 Published online: 13 Oct 2019.}

\section{Submit your article to this journal ¿}

\section{ШII Article views: 2335}

Q View related articles $ָ$ 


\title{
Beyond communication training: The MaRIS model for developing medical students' human capabilities and personal resilience
}

\author{
Kwong D. Chan ${ }^{a, b}$ (D), Linda Humphreys ${ }^{a, b}$ (D), Amary Mey ${ }^{a}$ (D) Carissa Holland ${ }^{b}$ (D) Cathy Wu ${ }^{b}$ (D) and \\ Gary D. Rogers ${ }^{a, b}$ (D) \\ ${ }^{a} G$ riffith Health Institute for the Development of Education And Scholarship (Health IDEAS), Griffith University, Gold Coast, Australia; \\ ${ }^{\mathrm{b}}$ School of Medicine, Griffith University, Gold Coast, Australia
}

\begin{abstract}
Purpose: Human capabilities in medicine, including communication skills, are increasingly important within the complex, challenging and dynamic landscape of healthcare. Supporting medical students to manage unavoidable role-related stressors adaptively may help mitigate the anguish that is too commonly reported among the profession. We developed a model, "MaRIS", underpinned by contemplative pedagogy, to support medical students to enhance their human capabilities, across all three domains of Bloom's taxonomy, and their personal resilience. It is the first to integrate Mindfulness, affective Reflection, Impactive experiences and a Supportive environment into medical curriculum design. Here, we describe the theoretical basis underpinning MaRIS and present a preliminary study to evaluate its impact on students' subjectively-rated capabilities.

Materials and Methods: A questionnaire capturing self-ratings of competence, empathy and resilience, as well as impressions of their experiences, was administered to foundation year medical students before (T0), during (T1) and after delivery (T2).

Results: Fifty-five students completed the survey at all time points. Mean scores for all domains increased significantly from T0 to T1 and from T0 to T2. Free-text comments suggest learning impact across the cognitive, psychomotor and affective domains. Conclusions: MaRIS appears to facilitate medical students' establishment of the foundations for building the human capabilities and personal resilience required for professional practice.
\end{abstract}

\section{Introduction}

Effective communication is essential for good medical practice ( $\mathrm{Ha}$ and Longnecker 2010; Slade et al. 2015). It is also well established that simulated learning activities involving repeated deliberate practice with feedback are an effective pedagogy for the acquisition of communication skills (Rogers et al. 2014; Papanagnou et al. 2018). However, navigating the complex human interactions inherent in healthcare practice - both between professionals and with patients and their significant others - requires a constellation of capabilities beyond the practical, trainable interpersonal skills that might be considered to reside primarily in the psychomotor domain of Bloom's time-honored taxonomy of learning outcomes (Bloom 1956). What we have come to call 'human capabilities' also include a sound, cognitive domain, understanding of what is known about effective communication and how to organize the information to be gathered or shared. Additionally, good practice requires the acquisition and demonstration of an underpinning set of professional values, in Bloom's affective domain, which the community demands of its health practitioners (Jha et al. 2006; Cruess and Cruess 2008), including a readiness to selfmonitor and improve performance continuously. The construct of 'empathy' has proven difficult to define (Frankel 2017; Dohrenwend 2018; Howick et al. 2018) but is not generally taken to emphasize the interplay between components across the three domains or the means by which they may be sustained among health workers (see below), hence our utilization of the term 'human capabilities.'

\section{Practice points}

- Escalating technological reliance in medicine, compounded by an inherently complex landscape, points to the increasing importance of human capabilities.

- Supporting medical students to manage unavoidable role-related stressors adaptively may help mitigate the anguish that is too commonly reported among the profession.

- The MaRIS model, underpinned by contemplative pedagogy, was designed to focus learning on all three domains of Bloom's taxonomy to support medical students to enhance their professional communication and medical history taking skills.

- In addition to facilitating clinical communication skill development, MaRIS has supported students' learning in all three domains of Bloom's taxonomy, resulting in a significant positive impact on their self-assessed communication skills, empathic ability, and resilience, in response to graded and supported exposure to controlled stressful experiences.

- MaRIS provides guidance for curriculum development that supports medical students to develop the human capabilities required for navigating the inherently complex landscape of contemporary medical practice. 
These capabilities have always been at the center of good medical practice (O'Donnabhain and Friedman 2018), but increasing utilization of technology for the investigation of disease and provision of treatment, with a concomitant risk of 'dehumanization,' underlines their ongoing importance. The future addition of artificial intelligence technologies to the diagnostic process and robotics for treatment delivery mean that interpersonal interaction is likely to constitute an even greater proportion of the daily work of health practitioners as machines come to perform many of their current tasks more effectively (Wartman and Combs 2018). Thus, practitioners are likely to spend less time engaged in making diagnoses and providing treatment, and more time engaged in the 'human' aspects of medicine. Further, the healthcare professionals of the future will need to be well equipped to communicate effectively and counsel patients regarding the outputs and uses of these new, sophisticated technologies.

The recent attention to distress and suicide among doctors-in-training (Dyrbye and Shanafelt 2016; Aubusson 2017) emphasizes that some of their most significant stressors, such as overwork and supervisor bullying (Kemp et al. 2019) are avoidable, highlighting the moral imperative to eradicate these conditions. Whilst this perspective is critically important, it must also be recognized that, even if these abhorrent sources of stress could be removed, the practice of medicine would remain inherently stressful due to its life and death nature, encountering patients and their significant others at the most difficult times in their lives. Further, acquisition of the high-level capabilities required for consultant practice requires an extended period of intense experiential learning with ongoing feedback to improve performance. Even where criticism is delivered appropriately and constructively, being informed by supervisors that one's practice requires further development remains personally challenging and necessitates emotional equanimity in learners.

Inability to respond positively to professional stresses (including those that are inherent and thus cannot be mitigated through, much needed, systematic change) is not only bad for doctors but also bad for patients. The association between practitioner distress and poor clinical performance, declining empathy and compromised patient safety is well established (Park et al. 2016; Panagioti et al. 2018). Thus, educational approaches enabling learners to develop their capacity to manage stress adaptively, which we might term 'personal resilience' (Teodorczuk et al. 2017; Kemp et al. 2019), remain a vital component in protecting doctors and their patients from adverse outcomes.

Optimally promoting the development of personal resilience among health professional students remains a vexed topic. A wide range of strategies has been reported (Howe et al. 2012; Passi 2014; Balme et al. 2015; Langendyk et al. 2016; Rogers 2016; Shakir et al. 2017), but most focus on the development of cognitive understandings of stress and its consequences or on the utilization of particular isolated skills such as mindfulness practice (Shakir et al. 2017). Conceptually, physicians' resilience has been seen as a developmental phenomenon, intimately linked with professional identity and sense of purpose (Winkel et al. 2019). Nonetheless, few studies to date have explored the importance of meaning and the connection to values in medical practice explicitly as a stress management strategy (Wald 2015a). Further, very few studies have focused attention on learning simultaneously across all three domains of Bloom's taxonomy with the goal of enhancing personal resilience (Branch 2015). Finally, despite decades of clinical experience with the use of graded exposure to manage anxiety responses in distressed individuals, and more limited application of 'stress inoculation' to enhance performance under pressure in the military and other settings (Joseph and Linley 2005; Stetz et al. 2007), the health professional education literature appears so far to have neglected the exploration of graded and supported exposure to controlled stressful experiences as a technique to build personal resilience.

Our work to formulate a learning model that enables health students to develop their human capabilities across the cognitive, psychomotor and affective domains, whilst also building their personal resilience, led us to the contemplative pedagogy (CP) framework (Zajonc 2013).

\section{Contemplative pedagogy}

$\mathrm{CP}$ is an approach to teaching and learning that empowers students to move beyond factual content to examine feelings and thoughts related to their learning experiences (Barbezat and Bush 2014). In this curricular first-person space, learners are supported to focus, observe and explore their internal world, enabling connection with their own values and sense of meaning. CP in medical education is a means to allow doctors-in-training to consider and incorporate who they are into their world, as well as how they might be changed by their learning and 'becoming' a doctor (Wald et al. 2015). Positive outcomes reported from CP practice include: enhanced focus and attention (Jha et al. 2007), improved cognition (Zeidan et al. 2010), increased cognitive flexibility (Moore and Malinowski 2009), enriched creativity and curiosity (Dyche and Epstein Ronald 2011) and a deepened sense of morality (Zajonc 2013).

$\mathrm{CP}$ comprises elements that, in concert, encourage complete attentiveness, aimed at supporting learners to comprehend their experience with deeper insight (Zajonc 2013). These include: mindfulness (deliberately and nonjudgmentally paying attention in the present moment, both a process and an outcome); active listening (hearing without judgement or attempts to control the conversation, finding a personal voice and hearing alternative voices); contemplation (the connection, compassion, thoughts and feelings that are internal to each individual, but also shared during interactions, equally exposing the vulnerability of each person and imparting authenticity to how each communicates with the other); beholding (intimately exploring and internalizing images and objects [and stories] through sustained attention, noticing detail, moving beyond the automatic response); and sustaining contradictions (the act of holding and honoring conflicting and contradictory world views and being comfortable with not knowing whether there is a correct answer).

\section{The MaRIS model}

Initial development of our medical program included a strong emphasis on what we then thought of as 'history 
taking and communication skills.' We developed 21 practical, three-hour workshops, recruited facilitators and trained simulated patients (SP) (Rogers, Chan, et al. 2017). Facilitators (including psychologists, counselors, nurses, social workers, and pharmacists, as well as some medical practitioners) were purposefully selected for their interest in the human dimensions of healthcare and their ability to promote a safe learning environment.

Interactive large group learning sessions (LGS) precede workshops, encompassing cognitive dimensions of the topic and introducing the skills to be developed. Then students work in groups of six, with a facilitator, to focus on a specific area of medical symptomatology, or a particular patient group. Workshops begin with a review of LGS content, followed by each student consulting with one of six SPs. Each SP portrays a real-life scenario, rotating between groups and playing the same character. After the consultation, students self-appraise their performance before receiving feedback from the SP, peers, and finally, the facilitator. Sharing of personal experience and feelings requires a protected space, with the facilitator's role being paramount (Young et al. 2016). Additionally, student groups remain together for multiple workshops over an extended period, fostering a collegial, supportive atmosphere.

We have since modified this fairly conventional structure, informed by $\mathrm{CP}$, as our conception of the constructs of 'human capabilities' and 'personal resilience' has grown. The approach has developed into a fully-formed pedagogical model that we have also applied to other activities such as Clinical Learning through Extended Immersion in Multimethod Simulation (CLEIMS) in later years of the medical program, described previously (Rogers et al. 2014; Rogers, Mey, et al. 2017; Rogers et al. 2018).

We noticed that learners found their first, fairly straight forward, encounters with SPs stressful, especially in the initial weeks. Consistent with trauma-informed pedagogy (Carello and Butler 2014), we prioritized a supportive environment, enabling students to manage this stress constructively. We observed that their anxiety diminished over several workshops with concurrent growth of personal resilience. Accordingly, we deliberately adjusted the scenarios and trained SPs to make the encounters more emotionally impactive. Learners' resilience appeared to strengthen as they gained mastery over more complex situations such as discussion of sexual matters, management of emotionally aroused patients and 'breaking bad news.'

For some students, the stress induced even at the beginning of the process was higher than the optimal levels for successful learning and graded exposure. Based on the extensive evidence supporting mindfulness in medical schools (Daya and Hearn 2018), we introduced a simple, secular mindfulness exercise at each workshop's commencement to assist learners in preparing for the challenges ahead. This has expanded to encompass promotion of a mindful approach to the entirety of each workshop and then to all aspects of students' learning and future practice (Amutio-Kareaga et al. 2017; Shakir et al. 2017; Daya and Hearn 2018).

We also utilize reflection as a metacognitive process that includes connection with feelings (Wald 2015b). Initially, we facilitated 'live' reflection and subsequently added written reflective journaling and summative

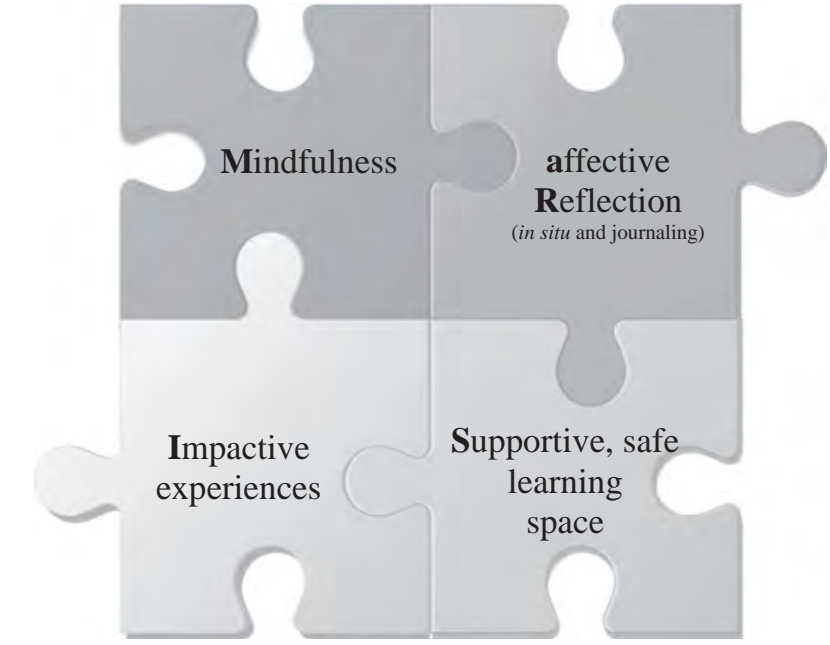

Figure 1. The MaRIS Model.

assessment of affective learning to encourage student engagement (Rogers, Mey, et al. 2017; Rogers et al. 2018). We now include scaffolded reflective writing, where students first learn the purposes and principles of reflection through LGS, then write formatively-assessed accounts, prior to summative assessment of later journals utilizing the Griffith University Affective Learning Scale (Rogers et al. 2018). This approach enables us to illuminate students' experiential processing and professional identity development (Wald et al. 2019) whilst concomitantly identifying students requiring additional support. Issues that become apparent through facilitator debriefs or students' reflective journals are managed through an established pathway that allows for targeted and appropriate additional support to be provided.

In summary, our model is grounded in four equally weighted, interlinked components represented by the acronym MaRIS (Figure 1): students engage in Mindfulness practice and affective Reflection (in situ and through journaling), whilst being deliberately and progressively exposed to emotionally Impactive (simulated) clinical experiences delivered in a Supportive and safe environment. While the literature is rich with evidence supporting the benefits of each of these elements (Branch 2015; Daya and Hearn 2018), we believe that we are the first to report the coherent utilization of all four core elements and to evaluate their impact on learning through multiple approaches.

\section{Methods}

We have undertaken multiple studies to evaluate the impact of MaRIS. Here, we present our preliminary study focused on self-reported communication competence, empathy, and resilience. The findings from our other studies to evaluate the impact of MaRIS will be reported separately. The research highlighted the absence of instruments designed to capture learners' self-assessments of their capabilities across all domains targeted by the program. The MaRIS Impact Questionnaire (MIQ) was therefore developed to meet this purpose.

\section{Development of the MIQ}

The MIQ comprised three sections. The first sought demographic information such as gender, age, prior 
Table 1. Items for assessment of competence, empathy, and resilience and prompting questions inviting participant comments.

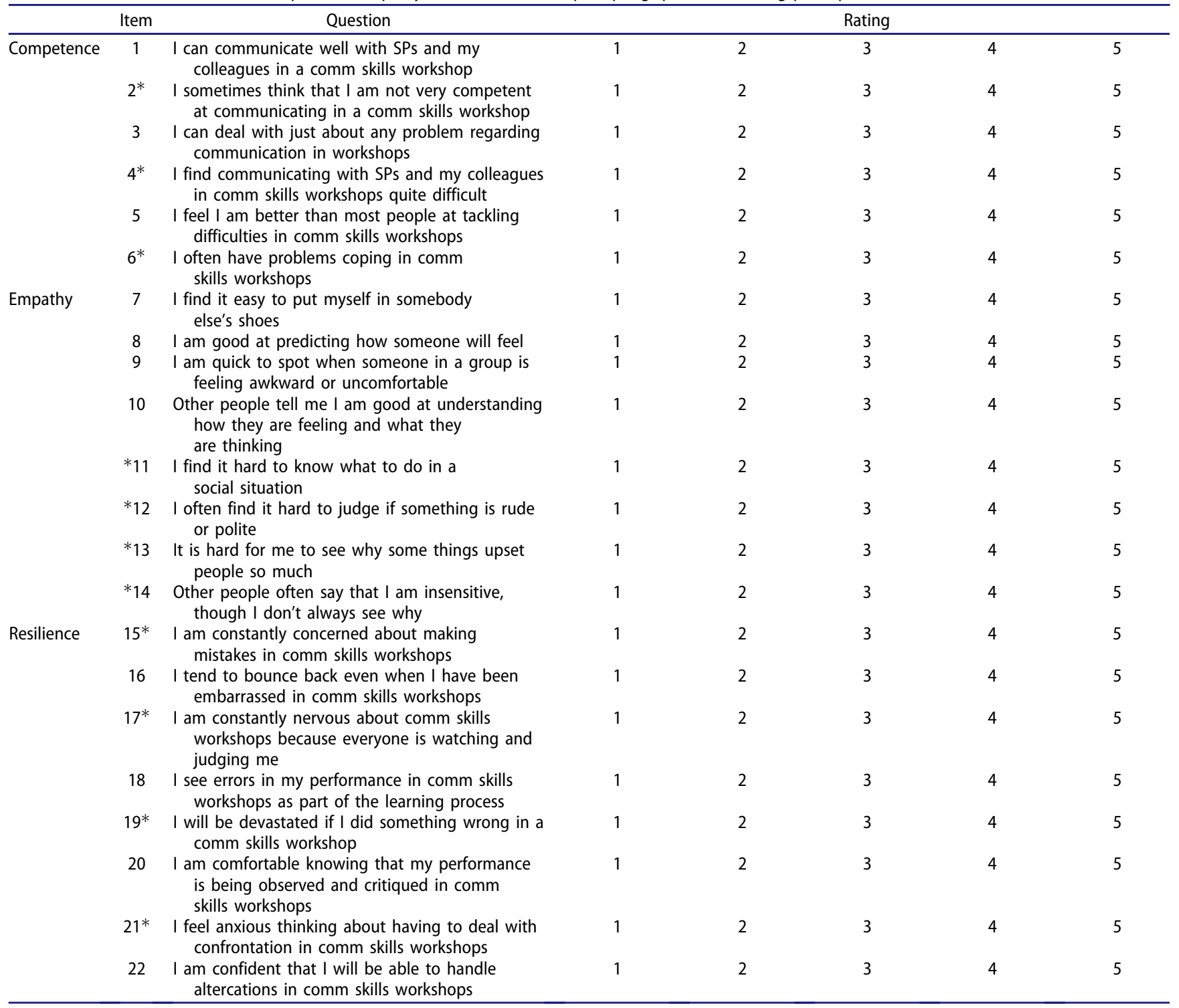

Please answer the two open question below:

Q1 On top of basic communication skills and history taking, did you learn anything else from the comm skills workshop? If so, please provide more details.

Q2 Do you think the comm skills workshops facilitate you and or your classmates in developing resilience? If so, please give some examples.

1: Strongly disagree; 2: Disagree; 3: Neutral; 4: Agree; and 5: Strongly agree.

qualifications and any prior experience as a health practitioner. The second comprised 22 statements, each requiring rating on a 5-point Likert scale. These items together formed the Competence Scale (CS), Empathy Scale (ES) and Resilience Scale (RS). They were developed by adapting tools previously used in other settings. Exemplar questions are presented in Table 1. Scores for negatively worded items (marked ${ }^{\left({ }^{\prime} \prime\right.}$ ) were reversed prior to analysis.

CS development drew on a previously validated instrument for measuring affective well-being and self-reported competence (Warr 1990), amended to reflect our test population (medical students) and task (communicating). The ES, also informed by an established instrument (Loewen et al. 2010), measured understanding of emotions, feelings and concerns. RS development was informed by validated and non-validated instruments (Campbell-Sills and Stein 2007; Siebert 2018). The RS captured feelings and concerns when faced with challenges. Higher values within each scale indicate greater self-perceived competence, empathy, and resilience, respectively.
The third section of the MIQ comprised open-ended questions inviting participants to describe what they gained from the workshops.

\section{Data collection and analysis}

Ethical clearance was granted by the Griffith University Human Ethics Committee (GU: 2016/821). Students were invited to participate via email and in-person. They were informed that participation required completion of the MIQ at three separate time points and permission to analyze and quote their writings. Participants were reassured of data de-identification and that their decision to participate would have no bearing on marks or their relationship with the research team.

The MIQ was administered to the student cohort in March ( $T 0$ - prior to commencement), June ( $T 1$ - after delivery of the 14th workshop) and October, 2017 (T2 after the 21 st workshop was undertaken). 
Quantitative data were prepared for analysis by tabulation onto SPSS ${ }^{\circledR}$ Version 24. The objective of the analysis was to determine whether mean scores for the scales changed over time, utilizing paired t-tests (Field 2009). Qualitative data were uploaded to NVivo Version 12 and analyzed thematically (Braun and Clarke 2012).

\section{Results}

One hundred and twenty, 117 and 104 questionnaires were returned at $T 0, T 1$, and $T 2$ respectively. After excluding incomplete questionnaires, 55 matched sets of data were analyzed.

\section{Participants}

Participants ( $n=26$ male, $n=29$ female), ranged in age between 19 and 35 years (mean $=22.4 \pm 3.4$ ). The majority (71.4\%) held a Bachelor level qualification and had no prior healthcare practice experience (Table 2).

At baseline, participants perceived themselves as moderately competent (mean $=3.31 \pm 0.74$ ), somewhat resilient (mean $=3.51 \pm 0.68$ ) and quite empathic (mean = $3.72 \pm 0.50)$. They did not differ when compared according to age or gender. However, participants with higher qualifications and those with prior healthcare practice experience reported significantly higher baseline CS scores than their counterparts ( $p=0.03$ and $p=0.02$, respectively).

Table 2. Participant characteristics.

\begin{tabular}{lcc}
\hline & $n$ & $\%$ \\
\hline Total & 55 & 100.0 \\
Gender & & \\
$\quad$ Male & 26 & 47.3 \\
$\quad$ Female & 29 & 52.7 \\
Age range (years) & & \\
$\quad \leq 21$ & 29 & 52.7 \\
$\quad \geq 22$ & 26 & 47.3 \\
Qualification & & \\
$\quad$ Bachelor & 41 & 74.5 \\
$\quad$ Honours or higher & 14 & 25.5 \\
Prior healthcare experience & & \\
$\quad$ Yes & 15 & 27.3 \\
$\quad$ No & 40 & 72.7 \\
\hline
\end{tabular}

\section{Change in self-assessed competence, empathy, and resilience across time}

The mean CS, ES, and RS at $T 0, T 1$, and $T 2$ are illustrated in Figure 2.

Mean scores for all domains increased significantly from $T 0$ to $T 1$ and from $T 0$ to $T 2$, however, $T 1$ to $T 2$ scores did not differ significantly (Table 3 ).

At 72 , group comparisons revealed no significant differences in CS, ES or RS scores. This indicates that participants who were less qualified and lacking healthcare practice experience were no longer distinguishable from their more educated and experienced peers.

\section{Modulators of competence, empathy, and resilience}

Responses to open-ended questions were rich with evidence of learning across the cognitive, psychomotor and affective domains that appeared to arise from the core components of MaRIS. Themes presented are exemplified by quotes, accompanied by participants' unique codes and a capitalized $\mathrm{F}$ or $\mathrm{M}$ to indicate their gender.

Participants described having gained numerous capabilities through their workshop experiences. Some reported that feedback from peers and facilitators enabled them to become aware of their own psychomotor behaviors (e.g. fidgeting) that were barriers to effective communication and learned strategies to overcome them. In the cognitive domain, most reported that structural acronyms (abbreviations of guided questions) provided them with a roadmap for directing their interactions. Others reported that they had gained a deeper understanding of themselves, the patient and their future role in the affective domain.

Table 3. Change in mean scores over time.

\begin{tabular}{lcccc}
\hline Comparison & Mean of difference & Standard deviation & $t$ & $p$ \\
\hline$T 1$ vs. $T 0$ & & & & \\
Competence & 0.29 & 0.61 & 3.58 & 0.001 \\
Empathy & 0.13 & 0.35 & 2.71 & 0.009 \\
$\quad$ Resilience & 0.17 & 0.52 & 2.45 & 0.018 \\
$T 2$ vs. $T 1$ & & & & \\
Competence & 0.09 & 0.44 & 1.50 & 0.139 \\
Empathy & -0.02 & 0.31 & -0.41 & 0.686 \\
Resilience & 0.09 & 0.55 & 1.17 & 0.249 \\
$T 2$ vs. $T 0$ & & & & \\
Competence & 3.85 & 0.67 & 4.28 & $<0.001$ \\
Empathy & 0.11 & 0.41 & 2.05 & 0.045 \\
Resilience & 0.26 & 0.56 & 3.46 & 0.001 \\
\hline
\end{tabular}

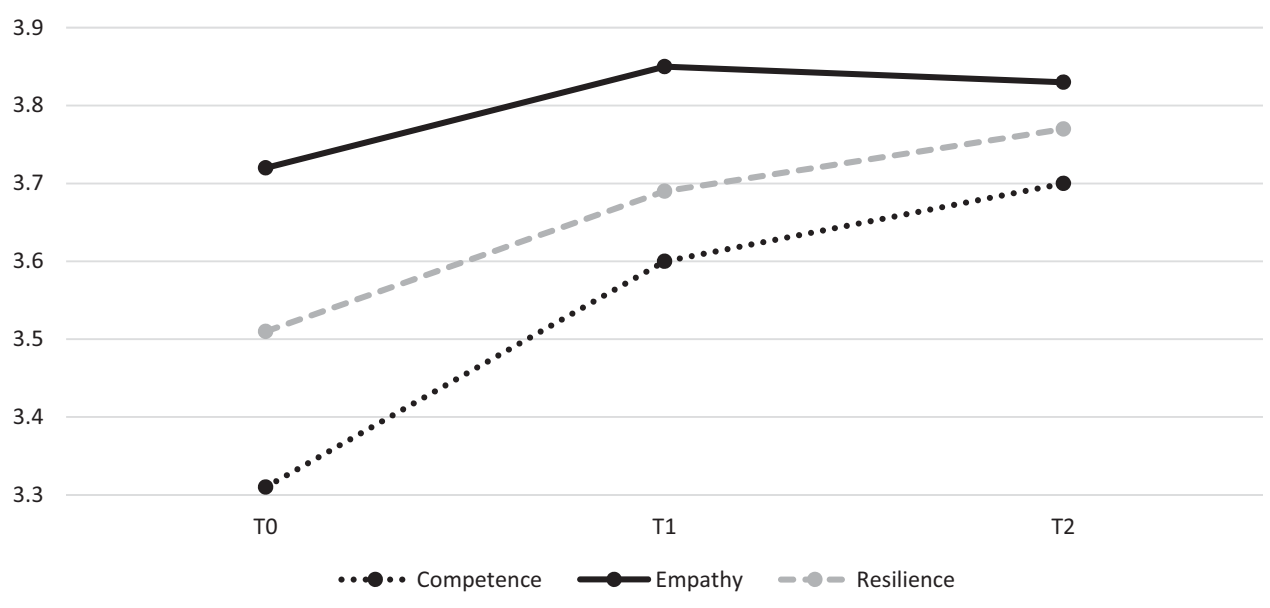

Figure 2. Change in mean CS, ES, and RS score. 
Some reported that they were able to exert control over their breathing and slow down their speech by practicing mindfulness, thereby allowing the interaction to unfold:

I learnt the power of silence and active listening in allowing myself to take the back seat and to allow the patient ... to explain their feelings and concerns ... 8253F

Conversations that progressed naturally were reported to facilitate the establishment of rapport that enhanced trust and encouraged open communication:

Starting with asking the patient to talk more about their family, people who they are close to/important to them is an effective way in building the rapport and trust which allows the later exchange to be smoother ... 9133F

Comfort with silence was reported to be important for allowing thought organization, thus helping with recognizing and responding appropriately to the patient's needs. Mindfulness practice was also reported to enable surmounting of personal barriers to communication that extended beyond the confines of doctor-patient interactions:

... mindfulness has helped me break out of the vicious cycle of anxiety - very grateful for it ... 10445M

Through open communication, participants reported that they were able to gain a deeper, more holistic understanding of the patient that went beyond the immediate clinical presentation, alongside their own capacity to provide care:

.. human emotion is a very complex form of expression. What meets the eye is not always the underlying feelings and, as a doctor, my job is not only to diagnose and treat, but to accentuate all my 5 senses so that I am able to recognise my patient's thoughts and feelings and respond appropriately ... 23592F

Some reported that understanding the patient's perspective also helped them to become aware of their own judgments, prejudicial attitudes and actions and modulate their behavior accordingly:

... I need to be mindful of the presence of others ... my own values and beliefs should not enter into interactions ... my role is to be objective and nonbiased and supportive to the patient .. 18707M.

Others reported that making mistakes and having their performance critiqued were daunting experiences, but explicitly identified that these experiences helped to develop their resilience:

... having a safe space to make mistakes and get feedback over lots of sessions helps to build resilience because you have to move on/pick yourself up after a bad session and try and improve on the next one. I think getting honest feedback also helps to build resilience ... 7629F

\section{Discussion}

In this report we have discussed the theoretical constructs underpinning the development of MaRIS, a model to build the human capabilities and personal resilience of medical students. We also present the findings from the first of our studies exploring the impact of MaRIS. Contemporary literature review reveals increasing awareness of the need to support students in developing capabilities that extend beyond the traditional psychomotor and cognitive domains (Sternlieb 2015; Wald et al. 2015; Sulzer et al. 2016; Shakir et al. 2017; Roth et al. 2018). Further, there is an urgency for guidance in the development of curricula that recognize and address these needs (Erschens et al. 2019; Kötter et al. 2019). We have elaborated a well-developed model, evaluated with a range of methodologies presented in this report and the paper to follow. MaRIS uniquely incorporates - and equally weights - mindfulness, affective reflection, impactive experiences and a supportive environment for medical student development. We have previously demonstrated that, for senior students, curriculum design incorporating three of the components of MaRIS (impactive experiences, affective reflection and a supportive environment) was more effective than traditional approaches (Rogers et al. 2014; Rogers, Mey, et al. 2017). Although developed independently, the MaRIS model shows 'convergent evolution' with programs developed in the United States and described by Branch (Branch 2015). MaRIS is distinguished from Branch's work by the deliberate creation of emotionally impactive learning experiences, the addition of mindfulness practice, explicit underpinning by the tenets of CP (Komjathy 2017) and a focus across the domains of Bloom's taxonomy (Bloom 1956).

Here, we have demonstrated that MaRIS has a positive impact on the development of self-assessed human capabilities of communication competence, empathic capacity and emotional resilience. Scores for all three scales significantly increased when evaluated across time. It is important to note that changes between $T 1$ and $T 2$ were not significant. This may suggest that a shorter program would be equally effective, but other explanations should be considered. First, the later part of the program may consolidate and integrate the learning that has already occurred. This kind of effect, informally identified and expressed by program facilitators, might be less apparent to the learner and thus less likely to be identified by self-assessment. The detailed qualitative part of the study, to be reported in a second paper, also suggests that the learning in the later part of the program occurs particularly in the affective domain and thus may be less apparent to learners. Second, as learners enhance their capability, they also become more attuned to the complexities of doctor-patient interaction and thus more critical of their own development. While we have demonstrated that differences in selfassessed capability related to prior experience at baseline were effaced post-experience, a further study with larger sample size is necessary to understand any differential effectiveness based on student characteristics.

Changes in each outcome followed a similar pattern, with the largest increase observed for self-rated communication competence, followed by resilience, then empathy. These findings may relate to the relative complexity of each construct under investigation, which is supported by our analysis of the questionnaire's qualitative component. For example, most participants reported that they had gained technical skills facilitating smooth interactions, such as how to apply mnemonics, pacing the conversation and active listening, thereby enhancing their confidence and perception of communication competence. While less often reported, failing to achieve the desired outcome and being able to 'fail' in a safe space (Kisfalvi and Oliver 2015) without consequence to real patients was acknowledged to increase the desire to reattempt and to strive for improvement. Sub-optimal 
performance and being provided with feedback also encouraged experimentation with different approaches, suggesting the development of personal resilience. Some participants' comments indicated awareness of the interplay of attitudes, beliefs, and circumstances that impact their ability to understand the patient's perspective and, therefore, to empathize. Our assertion that targeted communication skills training can enhance students' perceptions of empathy is receiving support (Hojat et al. 2013). However, whether empathy is sustained or enhanced long-term is not able to be determined. Indeed, a recent study suggests the need for repeated exposure to empathy-enhancing activities in order to reinforce the cognitive dimensions of empathic communication with patients continuously (Kataoka et al. 2019). Further, students' learning in the affective domain could not be fully elucidated from the brief responses analyzed in the current study. Phenomenologically-informed analysis of reflective journals and qualitative interviews will be presented in a second paper.

MaRIS appeared to support students to develop their self-rated human capabilities, but this study has some limitations. The scales in our questionnaire have not been previously validated for application with medical students. A range of validated scales related to particular potential outcomes of the program has been reported in the literature (Connor and Davidson 2003; Campbell-Sills an Stein 2007; O'Connor et al. 2014; Dohrenwend 2018; Moreto et al. 2018) but, given the longitudinal and multicomponent nature of the research, for the purpose of this preliminary investigation we chose to combine instruments to create a brief tool to minimize the burden on participants. We also refrained from making inferences about findings from the scales alone. Instead, where noting findings of interest, we sought to utilize our analysis of the qualitative component of the questionnaire to clarify their meaning.

\section{Conclusions}

We have described the development and theoretical underpinnings of the MaRIS model, which appears to facilitate medical students' establishment of the foundations for building the human capabilities and personal resilience required for effective professional practice. The current study offers a limited understanding of the processes underpinning enhanced self-perception. Phenomenological analysis of learners' reflections in a second paper will clarify when and how these changes occur. With the current study being limited to first-year medical students, future research should explore the impact of the MaRIS model on senior medical students and graduates whose journey began in the MaRIS-based workshops, as well as the model's applicability to students from other health professions.

\section{Acknowledgments}

The authors wish to thank the participants for their valued contribution to the research.

\section{Disclosure statement}

The authors report that they have no conflicts of interest related to this publication.

\section{Glossary}

Affective reflection: Describes attention to, and exploration of emotional responses to experience in the context of personally held values, beliefs and assumptions. Affective reflection is a core element of critical reflection in medicine, defined as 'connecting with feelings that occur before, during and after situations with the purpose of developing greater awareness and understanding of both the self, other and the situation, so that future encounters with the situation, including ways of being, relating and doing are informed from previous encounters.' (Wald 2015b)

An impactive experience: Is an experience in health professional education that induces an emotional response in the learner. Such experiences may occur in real patient or client care settings or be designed in simulated settings with the deliberate intention to facilitate affective domain learning (attitudes, values and appreciations) alongside the acquisition of trainable skills in the psychomotor domain and the development of cognitive domain knowledge. (Rogers, Mey, et al. 2017)

A supportive environment in experiential learning: Is a transitional space that is not always comfortable but one where any discomfort or vulnerability is contained through a culture of openness, a willingness to share and high-quality listening (Kisfalvi and Oliver 2015). This is central to reflexive practice, and a prerequisite to support affective reflection more specifically, which involves attending to personal feelings and meaning-making in the context of one's beliefs and values.

\section{Notes on contributors}

Kwong Djee Chan, MD, MA (Life and Death Studies), PhD, is a Senior Lecturer of Medical Education and the Communication Skills Stream Lead of the School of Medicine at Griffith University. He is also the Adjunct Deputy Director of the Humanizing Health Professional Education Research Center at Kaohsiung Medical University.

Linda Humphreys, MSc (Genetic Counseling), Grad Cert (Higher Education), BSC (hons), is Lecturer of Medical Education and the Reflective Practice Lead of the School of Medicine at Griffith University.

Amary Mey, BPharm(Hons), PhD, is a Lecturer of Pharmacy of the School of Pharmacy and Pharmacology and a Research Fellow in Learning and Teaching Scholarship of the Griffith Health Institute for the Development of Education and Scholarship (Health IDEAS), at Griffith University

Carissa Holland, BBiomedSci, is a final year medical student at Griffith University.

Cathy Wu (Chao-yuan), BEdu (Health Education), MSci (Medicine), PhD, focused on data management and analysis of quantitative research, at Griffith University.

Gary D. Rogers, MBBS, PhD, is Professor of Medical Education and Deputy Head (Learning \& Teaching) of the School of Medicine at Griffith University, in addition to a role as Program Lead for Interprofessional and Simulation-Based Learning in the Griffith Health Institute for the Development of Education and Scholarship (Health IDEAS).

\section{ORCID}

Kwong D. Chan (iD http://orcid.org/0000-0003-0585-151X

Linda Humphreys (iD http://orcid.org/0000-0002-5149-320X

Amary Mey (iD http://orcid.org/0000-0002-5339-5101

Carissa Holland (ID http://orcid.org/0000-0003-4201-1763

Cathy Wu iD http://orcid.org/0000-0002-3964-1564

Gary D. Rogers (iD http://orcid.org/0000-0003-4655-0131 


\section{References}

Amutio-Kareaga A, García-Campayo J, Delgado LC, Hermosilla D, Martínez-Taboada C. 2017. Improving communication between physicians and their patients through mindfulness and compassionbased strategies: a narrative review. JCM. 6(3):33.

Aubusson K. 2017. July 5. 'She was eaten alive': Chloe Abbott's sister Micaela's message for the next generation of doctors. The Sydney Morning Herald. [accessed 2017 Mar 25]. https://www.smh.com.au/ healthcare/she-was-eaten-alive-dr-chloe-abbotts-sister-micaelas-message-for-the-next-generation-of-doctors-20170704-gx4jt3.html.

Balme E, Gerada C, Page L. 2015. Doctors need to be supported, not trained in resilience. BMJ. 351:h4709.

Barbezat DP, Bush M. 2014. Contemplative practices in higher education: powerful methods to transform teaching and lerning. San Francisco (CA): Jossey-Bass/Wiley.

Bloom B. 1956. Taxonomy of educational objectives, handbook 1: cognitive domain. New York (NY): Mckay.

Branch WT. 2015. Teaching professional and humanistic values: suggestion for a practical and theoretical model. Patient Educ Couns. 98(2):162-167.

Braun V, Clarke V. 2012. Thematic analysis. In Cooper H, Camic PM, Long DL, Panter AT, Rindskopf D, Sher KJ, editors. APA handbook of research methods in psychology, Vol 2: Research designs: Quantitative, qualitative, neuropsychological, and biological. Washington (DC): American Psychological Association; p. 57-71.

Campbell-Sills L, Stein MB. 2007. Psychometric analysis and refinement of the Connor-Davidson Resilience Scale (CD-RISC): validation of a 10-item measure of resilience. J Trauma Stress. 20(6):1019-1028.

Carello J, Butler LD. 2014. Potentially perilous pedagogies: teaching trauma is not the same as trauma-informed teaching. J Trauma Dissoc. 15(2):153-168.

Connor KM, Davidson JR. 2003. Development of a new resilience scale: the Connor-Davidson Resilience Scale (CD-RISC). Depr Anxiety. 18(2):76-82.

Cruess RL, Cruess SR. 2008. Expectations and obligations: professionalism and medicine's social contract with society. Perspect Biol Med. 51(4):579-598.

Daya Z, Hearn JH. 2018. Mindfulness interventions in medical education: a systematic review of their impact on medical student stress, depression, fatigue and burnout. Med Teach. 40(2):146-153.

Dohrenwend AM. 2018. Defining empathy to better teach, measure, and understand its impact. Acad Med. 93(12):1754-1756.

Dyche L, Epstein Ronald M. 2011. Curiosity and medical education. Med Educ. 45(7):663-668.

Dyrbye L, Shanafelt T. 2016. A narrative review on burnout experienced by medical students and residents. Med Educ. 50(1):132-149.

Erschens R, Keifenheim KE, Herrmann-Werner A, Loda T, SchwilleKiuntke J, Bugaj TJ, Nikendei C, Huhn D, Zipfel S, Junne F. 2019. Professional burnout among medical students: systematic literature review and meta-analysis. Med Teach. 41(2):172-183.

Field A. 2009. Discovering statistics using SPSS (3rd ed.). London (UK): Sage Publications Ltd.

Frankel RM. 2017. The evolution of empathy research: models, muddles, and mechanisms. Patient Educ Couns. 100(11):2128-2130.

Ha JF, Longnecker N. 2010. Doctor-patient communication: a review. Ochsner J. 10(1):38-43.

Hojat M, Axelrod D, Spandorfer J, Mangione S. 2013. Enhancing and sustaining empathy in medical students. Med Teach. 35(12): 996-1001.

Howe A, Smajdor A, Stockl A. 2012. Towards an understanding of resilience and its relevance to medical training. Med Educ. 46(4): 349-356.

Howick J, Bizzari V, Dambha-Miller H. 2018. Therapeutic empathy: what it is and what it isn't. J R Soc Med. 111(7):233-236.

Jha AP, Krompinger J, Baime MJ. 2007. Mindfulness training modifies subsystems of attention. Cogn Affect Behav Neurosci. 7(2):109-119.

Jha V, Bekker HL, Duffy SRG, Roberts TE. 2006. Perceptions of professionalism in medicine: a qualitative study. Med Educ. 40(10): 1027-1036.

Joseph S, Linley P. 2005. Positive adjustment to threatening events: an organismic valuing theory of growth through adversity. Rev Gen Psychol. 9(3):262-282.

Kataoka H, Iwase T, Ogawa H, Mahmood S, Sato M, DeSantis J, Hojat M, Gonnella JS. 2019. Can communication skills training improve empathy? a six-year longitudinal study of medical students in Japan. Med Teach. 41(2):195-200.

Kemp S, Hu W, Bishop J, Forrest K, Hudson J, Wilson I, Teodorczuk A, Rogers G, Roberts C, Wearn A. 2019. Medical student wellbeing - a consensus statement from Australia and New Zealand. BMC Med Educ. 19(1):69-69.

Kisfalvi V, Oliver D. 2015. Creating and maintaining a safe space in experiential learning. J Manag Educ. 39(6):713-740.

Komjathy L. 2017. Introducing contemplative studies. Hoboken, USA John Wiley \& Sons. Contemplative Pedagogy, Chapter 5, p. 159-199.

Kötter T, Fuchs S, Heise M, Riemenschneider H, Sanftenberg L, Vajda C, Voigt K. 2019. What keeps medical students healthy and well? a systematic review of observational studies on protective factors for health and well-being during medical education. BMC Med Educ. 19(1):94.

Langendyk V, Mason G, Wang S. 2016. How do medical educators design a curriculum that facilitates student learning about professionalism? Int J Med Educ. 7:32-43.

Loewen P, Lyle G, Nachshen J. 2010. An eight-item form of the empathy quotient (EQ) and an application to charitable giving. [accessed 2019 Mar 27]. http://individual.utoronto.ca/loewen/Rese arch_files/Eight\%20Question\%20ES_final.pdf.

Moore A, Malinowski P. 2009. Meditation, mindfulness and cognitive flexibility. Conscious Cogn. 18(1):176-186.

Moreto G, Santos IS, Blasco PG, Pessini L, Lotufo PA. 2018. Assessing empathy among medical students: a comparative analysis using two different scales in a Brazilian medical school. Educación Médica. 19:162-170.

O'Connor K, King R, Malone KM, Guerandel A. 2014. Clinical examiners, simulated patients, and student self-assessed empathy in medical students during a psychiatry objective structured clinical examination. Acad Psychiatry. 38(4):451-457.

O'Donnabhain R, Friedman ND. 2018. What makes a good doctor? Intern Med J. 48(7):879-882.

Panagioti M, Geraghty K, Johnson J, Zhou A, Panagopoulou E, ChewGraham C, Peters D, Hodkinson A, Riley R, Esmail A. 2018 Association between physician burnout and patient safety, profes sionalism, and patient satisfaction: a systematic review and metaanalysis. JAMA Intern Med. 178(10):1317-1331.

Papanagnou D, Lee H, Rodriguez C, Zhang XCC, Rudner J. 2018. Not your typical simulation workshop: using LEGOs to train medical students on the practice of effective communication. Cureus. 10(1): e2094.

Park C, Lee YJ, Hong M, Jung C-H, Synn Y, Kwack Y-S, Ryu J-S, Park TW, Lee SA, Bahn GH. 2016. A multicenter study investigating empathy and burnout characteristics in medical residents with various specialties. J Korean Med Sci. 31(4):590-597.

Passi V. 2014. Developing resilience throughout the continuum of medical education. Perspect Med Educ. 3(5):329-331.

Rogers D. 2016. Which educational interventions improve healthcare professionals' resilience? Med Teach. 38(12):1236-1241.

Rogers G, Chan P, Bancroft L, Chan K, Humphreys L, Ellem F. 2017. Evaluating the effectiveness of the world's first for-credit course to develop simulated patients. Paper presented at the 4th International Conference on Faculty Development in the Health Professions; Aug 25-27; Helsinki, Finland.

Rogers G, McConnell H, Jones de Rooy N, Ellem F, Lombard M. 2014. A randomised controlled trial of extended immersion in multi-method continuing simulation to prepare senior medical students for prac tice as junior doctors. BMC Med Educ. 14(1):90.

Rogers G, Mey A, Chan P. 2017. Development of a phenomenologically derived method to assess affective learning in student journals following impactive educational experiences. Med Teach. 39(12): 1250-1260.

Rogers G, Mey A, Chan P, Lombard M, Miller F. 2018. Development and validation of the Griffith University Affective Learning Scale (GUALS): a tool for assessing affective learning in health professional students' reflective journals. MedEdPublish. 7(1):2.

Roth CG, Eldin KW, Padmanabhan V, Friedman EM. 2018. Twelve tips for the introduction of emotional intelligence in medical education Med Teach. 41(7):746-749.

Shakir HJ, Recor CL, Sheehan DW, Reynolds RM. 2017. The need for incorporating emotional intelligence and mindfulness training in modern medical education. Postgrad Med J. 93(1103):509-511. 
Siebert A. 2018. Al Siebert Resiliency Centre. Resiliency quiz - how resilient are you? [accessed 2018 Sept 30]. https://resiliencyquiz. com/index.shtml

Slade D, Manidis M, McGregor J, Scheeres H, Chandler E, SteinParbury J, Dunston R, Herke M, Matthiessen C. 2015. Communicating in hospital emergency departments. Berlin (Germany): Springer-Verlag.

Sternlieb J. 2015. A guide to introducing and integrating reflective practices in medical education. Int J Psychiat Med. 49(1):95-105.

Stetz MC, Thomas ML, Russo MB, Stetz TA, Wildzunas RM, McDonald JJ, Wiederhold BK, Romano JA, Jr. 2007. Stress, mental health, and cognition: a brief review of relationships and countermeasures. Aviat Space Environ Med. 78(5):B252-B260.

Sulzer SH, Feinstein NW, Wendland C. 2016. Assessing empathy development in medical education: a systematic review. Med Educ. 50(3) 300-310.

Teodorczuk A, Chan K, Thomson R, Rogers G. 2017. When I say ... resilience. Med Educ. 51(12):1206-1208.

Wald H. 2015a. Professional identity (trans)formation in medical education: reflection, relationship, resilience. Acad Med. 90(6):701-706.

Wald H. 2015b. Refining a definition of reflection for the being as well as doing the work of a physician. Med Teach. 37(7):696-699.

Wald HS, Anthony D, Hutchinson TA, Liben S, Smilovitch M, Donato AA. 2015. Professional identity formation in medical education for humanistic, resilient physicians: pedagogic strategies for bridging theory to practice. Acad Med. 90(6):753-760.

Wald HS, White J, Reis SP, Esquibel AY, Anthony D. 2019. Grappling with complexity: medical students' reflective writings about challenging patient encounters as a window into professional identity formation. Med Teach. 41(2):152-160.

Warr P. 1990. The measurement of well-being and other aspects of mental health. J Occup Psychol. 63(3):193-210.

Wartman SA, Combs CD. 2018. Medical education must move from the information age to the age of artificial intelligence. Acad Med. 93(8):1107-1109.

Winkel AF, Robinson A, Jones AA, Squires AP. 2019. Physician resilience: a grounded theory study of obstetrics and gynaecology residents. Med Educ. 53(2):184-194.

Young JE, Williamson MI, Egan TG. 2016. Students' reflections on the relationships between safe learning environments, learning challenge and positive experiences of learning in a simulated GP clinic. Adv in Health Sci Educ. 21(1):63-77.

Zajonc A. 2013. Contemplative pedagogy: a quiet revolution in higher education. NDTL. 2013(134):83-94.

Zeidan F, Johnson SK, Diamond BJ, David Z, Goolkasian P. 2010. Mindfulness meditation improves cognition: evidence of brief mental training. Conscious Cogn. 19(2):597-605. 